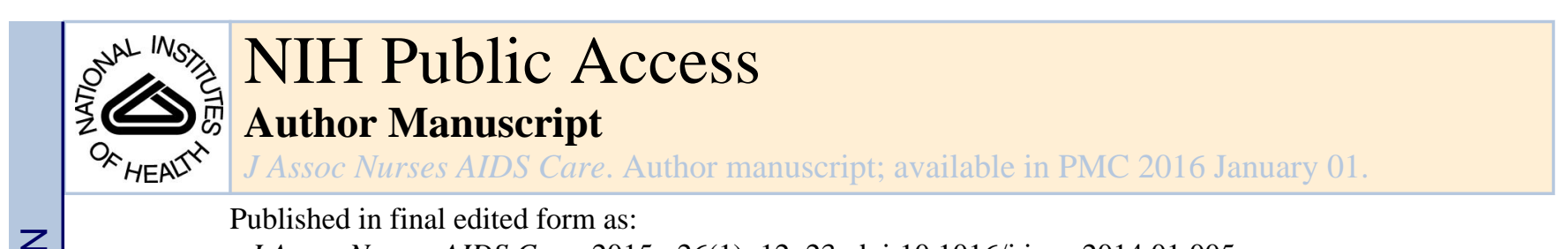

J Assoc Nurses AIDS Care. 2015 ; 26(1): 12-23. doi:10.1016/j.jana.2014.01.005.

\title{
"I Should Know Better": The Roles of Relationships, Spirituality, Disclosure, Stigma, and Shame for Older Women Living with HIV Seeking Support in the South
}

\author{
Catherine A. Grodensky, MPH, \\ Manager, Social and Behavioral Sciences Research Core Center for AIDS Research, University \\ of North Carolina at Chapel Hill, Chapel Hill, NC, USA \\ Carol E. Golin, MD, \\ Director, Social and Behavioral Sciences Research Core Center for AIDS Research; Associate \\ Professor, Gillings School of Global Public Health, Department of Health Behavior; and Associate \\ Professor, Division of General Medicine, School of Medicine, University of North Carolina at \\ Chapel Hill, Chapel Hill, NC, USA \\ Chaunetta Jones, MPH, \\ Research Assistant, Social and Behavioral Sciences Research Core Center for AIDS Research, \\ University of North Carolina at Chapel Hill, Chapel Hill, NC, USA during the conduct of this study. \\ She currently is a Research Fellow, Office of Health Communication and Education, Food and \\ Drug Administration Center for Tobacco Products, Rockville, MD, USA
}

Meheret Mamo, BA,

Research Assistant, Social and Behavioral Sciences Research Core Center for AIDS Research, University of North Carolina at Chapel Hill, Chapel Hill, NC, USA

\begin{abstract}
Alexis C. Dennis, BA,
Research Assistant, Social and Behavioral Sciences Research Core Center for AIDS Research, University of North Carolina at Chapel Hill, Chapel Hill, NC, USA

Melinda G. Abernethy, MD, MPH, and

Student at the Gillings School of Global Public Health University of North Carolina during the conduct of this study and is currently Urogynecology Fellow, Department of Obstetrics and Gynecology, Loyola University Stritch School of Medicine, Chicago, IL, USA
\end{abstract}

\section{Kristine B. Patterson, MD}

Associate Professor, Division of Infectious Diseases School of Medicine, University of North Carolina at Chapel Hill School of Medicine, Chapel Hill, NC, USA

\footnotetext{
(C) 2014 Association of Nurses in AIDS Care. Published by Elsevier Inc. All rights reserved.

Corresponding Author: Kristine Patterson, MD: Kristine_patterson@med.unc.edu.

Conflict of Interest Statement

The authors report no real or perceived vested interests that relate to this article that could be construed as a conflict of interest.

Publisher's Disclaimer: This is a PDF file of an unedited manuscript that has been accepted for publication. As a service to our customers we are providing this early version of the manuscript. The manuscript will undergo copyediting, typesetting, and review of the resulting proof before it is published in its final citable form. Please note that during the production process errors may be discovered which could affect the content, and all legal disclaimers that apply to the journal pertain.
} 


\section{Abstract}

The population of older people living with HIV in the United States is growing. Little is known about specific challenges older HIV-infected women face in coping with the disease and its attendant stressors. To understand these issues for older women, we conducted semi-structured indepth interviews with 15 women (13 African American, 2 Caucasian) 50 years of age and older (range 50-79) in HIV care in the Southeastern United States, and coded transcripts for salient themes. Many women felt isolated and inhibited from seeking social connection due to reluctance to disclose their HIV status, which they viewed as more shameful at their older ages. Those receiving social support did so mainly through relationships with family and friends, rather than romantic relationships. Spirituality provided great support for all participants, although fear of disclosure led several to restrict connections with a church community. Community-level stigmareduction programs may help older HIV-infected women receive support.

\section{Keywords}

aging; disclosure; HIV; social support; spirituality; stigma

Approximately one quarter of the estimated 1.2 million people living with HIV in the United States are over the age of 50 years (Centers for Disease Control and Prevention [CDC], 2008; CDC, 2012). By 2015, the proportion of HIV-infected individuals older than age 50 is estimated to increase to 50\% (Effros et al., 2008). This increase is due in part to the rising number of new HIV diagnoses among this group (15\% of new HIV cases in 2009; CDC, 2012; Stark, 2007), and in part to decreased mortality as a result of successful treatment with antiretroviral (ARV) medications, allowing more HIV-infected people to live into old age (Sankar, Nevedal, Neufeld, Berry, \& Luborsky, 2011).

Research has suggested that older people may experience living with HIV differently than those who are younger. Generally, older patients have been found to be more adherent to their ARV medications than younger patients, but their adherence is more sensitive to weakened cognitive function and substance abuse problems (Barclay et al., 2007; Ettenhofer et al., 2009; Hinkin et al., 2004). Similarly, the experience of aging may differ between those who are living with HIV and those who are not. For example, Rabkin, McElhiney, and Ferrando (2004) found that rates of depression and substance use, which typically decline with increasing age in the general population (Byers, Yaffe, Covinsky, Friedman, \& Bruce, 2010; Gum, King-Kallimanis, \& Kohn, 2009; Lincoln, Taylor, Chae, \& Chatters, 2010), do not similarly decline for individuals infected with HIV. Research has suggested that social support may be particularly important for older HIV-infected people. Social support confers benefits for older adults living with HIV, helping to mitigate distress and improve mood (Schrimshaw \& Siegel, 2003), while stigma and loneliness are associated with increased depressive symptomatology (Grov, Golub, Parsons, Brennan, \& Karpiak, 2010; Yi et al., 2006).

The particular challenges of older women living with HIV have not been separated from those of men. More specifically, the psychosocial experiences of older women living with HIV have not been fully described. Yet older women are at increased risk of contracting 
HIV as the likelihood of using condoms decreases with age and, accordingly, the estimated annual percentage of older women who acquired HIV heterosexually has been rising (Nguyen \& Holodniy, 2008). These trends indicate the increasing need to understand the experiences of older women living with HIV. The purposes of the project were to (a) investigate the important psychosocial factors impacting older women's living and coping with HIV infection, particularly in social and spiritual relationships, and (b) to explore relationships between those factors. To achieve these purposes, we conducted a qualitative study with 15 HIV-infected women ages 50 and older receiving HIV care in the Southeastern United States.

\section{Methods}

\section{Design}

In-depth, semi-structured, qualitative interviews were conducted with 15 women, with each interview lasting about 1 hour. The interview guide was designed to elicit information from the women on psychosocial aspects of their lives, particularly related to the diagnosis and management of their HIV, that would yield a thematic description of older women's experiences living with HIV (Sandelowski \& Barroso, 2003). Examples of the general questions used to invite exploration of these issues included, What are some challenging aspects of your day-today life? and How has your life changed since you were diagnosed with HIV? Women were also asked more specific probes to provide opportunities to elaborate on specific psychosocial factors such as social stressors and support, emotional reactions to aspects of living with HIV, perceptions of faith, and personal and social responsibilities. These probes were refined continuously during data collection to ensure exploration of relevant themes emerging in the interviews. Examples of such probes included, Tell me about your home and the people who live there. Are you responsible for the well-being of any of these individuals? and How has being HIV-infected affected any relationships in your life - with friends, family, sexual partner(s)?

\section{Study Sample and Setting}

This study took place at a public-hospital-based infectious diseases clinic. All women who were HIV-infected, English-speaking, ages 50 years or older, receiving care at the clinic between May 2006 and November 2006, and previously consented to be approached for research studies, were invited. Two women declined due to time constraints dictated by transportation departure times.

\section{Protection of Human Subjects}

Written informed consent was obtained before each interview. Interviews were held in a private location in the clinic. The institutional review board of the University of North Carolina at Chapel Hill approved the study protocol. The participants received a nominal monetary compensation of $\$ 15.00$ for participation in the study.

\section{Data Collection}

During the data collection period, each interview was transcribed verbatim and reviewed by the interviewer (MA) shortly after completion. The interviewer conducted continuous 
comparative analysis between transcribed interviews in groups of five, through which commonalities in the interviews were identified, categorized, and compared. The interviewer and principal investigator (KP) drew from the identified emerging themes in order to (a) inform the development and modification of question probes for subsequent interviews when further exploration or clarification of those themes was warranted for a more complete understanding of women's perspectives and experiences, and (b) determine whether theme saturation had occurred.

\section{Analysis of Qualitative Data}

At completion of data collection, a coding team of three researchers (CAG, CJ, MM) conducted open coding using cutting and sorting principles with all 15 transcripts (Ryan \& Bernard, 2003). First, they reviewed the transcripts and generated a list of codes based on important ideas that emerged from the data, which were often identified either linguistically, by noticing ideas or words that were repeated within or across subjects, metaphorical language, or comparisons made by subjects between different aspects of their lives; or thematically, by ideas that mapped onto important themes already demonstrated in the literature among HIV-infected women such as stigma, disclosure, and disease burden (Ryan $\&$ Bernard, 2003). Then they grouped the list of codes into conceptual categories or themes, which were refined into a codebook. The same three researchers each applied the codebook to code two randomly selected transcripts using NVivo 9 software, compared the codes they applied, resolved any discrepancies through discussion, and revised the codebook as needed based on that process. Final refinements to the codebook were made after applying a similar approach to five more transcripts. The remaining eight interviews were independently assigned codes. Finally, two of the researchers (CJ, CAG) conducted queries of coded interview text in NVivo (as a basis for representative quotes in the results) to further examine intersections of related codes and themes and to integrate them into a thematic description of living with HIV in this sample of women (Sandelowski \& Barroso, 2003).

\section{Results}

\section{Sample Characteristics}

The demographic features of the 15 study participants are shown in Table 1. Of the four sexually active women, one was married to an HIV-uninfected man, two had HIV-infected intimate partners (one was married to her partner and one referred to him as her boyfriend), and one reported occasional sexual activity with a male friend but did not specify his HIV status. Three of the four sexually active women reported consistent condom use; one woman reported inconsistent condom use with her HIV-infected partner.

\section{Overview of Findings}

The women discussed three types of relationships that were sources of potential or actual support in their lives: (a) family and platonic relationships, (b) romantic partnerships, and (c) relationships with a church community and with God. Within each type of relationship, salient themes emerged that reflected two general issues: (a) the types of support received, and (b) factors that helped or hindered accessing that potential source of support. 


\section{Family and Platonic Relationships}

The main sources of social support women listed were close family members. The women specifically mentioned their grown daughters as sources of social support, and described their daughters as helping with transportation to appointments, taking medications, meal preparation, and housing, as well as being someone with whom they could talk and have fun. Two of the older women in the sample relied on their daughters heavily for daily caregiving. The women also described their grandchildren as sources of support and happiness, by making them feel wanted and loved when the children visited. One woman described:

Well, I supposed to be living by myself. But my children and my grandkids... I never live alone. [LAUGHTER] Who I live with? I live with all my kids. I be around somebody all of the time. They come to visit. They come to see me, then they'll stay awhile, then they'll just come to say "hi" and they'll stay over-night. They come... They just come to stop by to say, "good morning." They're good. There's always somebody around.

Siblings and cousins were also cited as helping with transportation and being someone the women could talk to about important things. Other women reported having a couple of good friends they could talk to, most of whom were women. Two women reported platonic relationships with male friends.

Several women described being socially isolated, with limited support. Most lived by themselves, and a few said they had no one, only one or two people, or only paid caregivers with whom they could talk. One woman said, "I don't have anyone. My daughter, I guess, she lives with me. I don't talk to people, you know."

All 15 women reported limiting their social interactions largely because they did not want others to find out they had HIV infection. Only one woman reported disclosing to most of the people in her life, largely because a family member told others she had HIV without her permission. All of the women in the study said that they did not want certain people or, for some women, anyone in their personal lives, to know about their HIV status. As one woman explained,

I guess I feel like there has been something missing since I found out I have HIV. I don't do some of the things I used to do. You know, I used to cook for people and stuff. I stopped doing that. I don't know...just different things like that. I feel like I just can't be honest with people anymore now that I have HIV, because I haven't really told a lot of people. I haven't told anybody really. Just my sister, and my doctors, and another friend of mine, but that's it. My son and daughter don't know. It's just that I feel there is something missing, you know. I just can't do... I guess I could do... but I just don't do as much stuff as I used to. Just as far as other people are concerned, I just try to stay my distance.

The main reason women gave for not disclosing their HIV status to others was to prevent people from fearing contracting HIV through casual contact with them. As one woman described, 
I still haven't been able to tell my family because people are ignorant to the fact that you can't catch HIV or AIDS by touching anybody or being around them. I have a very loving family, and I just couldn't tell them because I just can't take the fact that I would be pushed away and shunned because I have this virus in my blood.

Some women justified their fears by relating instances in which people to whom they had not disclosed expressed fear of interacting with other HIV-infected people. One woman who worked as a medical professional reported that fellow staff members, "freak out when an HIV-positive patient comes into the clinic_it's difficult to see their reactions." Another woman said her family members avoided certain acquaintances known to have HIV. Also, many women had experienced others withdrawing from them after they disclosed: "Once somebody find out their attitude changes toward you."

Some women said their level of shame about having HIV, and subsequent social withdrawal, was higher because they were older. As one woman put it,

I guess that the older you get, the more isolated you feel because you kind of feel stupid. Like, how could I do ... I should know better. I should know not to have unprotected sex at my age. I should know better. So, I think that is on top of just feeling alone, you feel dumb.

One woman remembered that disclosure was helpful in coping with her initial diagnosis: "I just felt like if I didn't tell somebody I would explode. So, um, it was for my own survival that I couldn't keep it a secret."

\section{Romantic Relationships}

Only three women had a committed romantic partner with whom they were sexually active at the time of the interview, and one reported having an occasional sexual relationship with a male friend. Their descriptions of fulfillment and support derived from these relationships varied. One woman enjoyed a particularly supportive relationship with her husband. When asked where she turned for support, she described:

My husband. He's my best thing that's ever happened to me.... It's something just like when you have a bad day on the job like and need somebody to talk to. And I go home and I just talk to him and I pour my heart out and he will say, "Now, do you feel better now?" And I'm like, "Yeah, I do."

In contrast, despite having a boyfriend, another woman said that for support she turned to her "daughter and God. That's it." Another enjoyed spending time with her husband. The woman with the casual sexual relationship reported: "We just find comfort in intimacy. Everyone needs a little of that."

Many of the women who were not sexually active described the ending of past relationships due to choice, abandonment, or partner death. Of women who were in relationships at the time of HIV diagnosis, only one said she had remained in the relationship with the man who infected her. Some women described their sexual abstinence in absolute statements about themselves, such as, "I just don't have sex anymore" and "I don't do that." Others described 
their sexual inactivity only as a current state of affairs, "I don't have any sexual partners right now." None of the women without current intimate partnerships expressed desire for a sexual relationship. One woman sought companionship, "I would like to have a companion. Somebody I could go out to eat with, go bowling, go to the zoo. I've had these zoo tickets for a couple of years and I haven't used them."

Another woman described how the romantic and sexual aspects of her relationship with an HIV-uninfected partner decreased gradually after her diagnosis until she considered him to be more of a roommate. Eventually, she chose to stop having sex with him because they were not married and she wanted to feel closer to God. She said: "I just didn't think that it was right that we were having sex. But, really, we only stopped having sex a few months ago." Although they continued to live together, the woman described the relationship as involving very little interaction: "Every once in a while we talk, just not really one on one. He goes one way and I go mine."

The women were reluctant to enter into new relationships and listed several reasons for this disinclination, including fear of infecting others, fear of being rejected, lack of available men, and low prioritization of having sexual intercourse. One woman stated: "You can't find anybody... I don't want to look for anybody, trust me!” One woman recounted recently discouraging a relationship with a potential partner:

At first I was running him away 'cause ... This was a friend I was talking to ... He didn't know and I didn't know how to tell him I was positive and I wrote him a letter. And I told him in the letter. He still felt the same way but I still kinda' felt funny cause he don't got [HIV]. I feel funny like I'm a little bit dirty. I shouldn't ... I don't want to take chances with men like that. I be feeling funny like that. We friends but I still be feeling funny though. I don't feel sex with him. He told me we could and I happen to have [a condom] with me at the time. But, it's still like I don't want nobody to get sick like that.

Other women feared the stigma they would face if they disclosed their status to a new partner. One woman described:

I guess maybe I don't trust telling anyone because once I ... If I get into a relationship and I tell them and my childrens are around, then they are, you know ... I don't know. I just don't want to and then I wouldn't feel safe. I wouldn't feel ... Well, I feel that most people are not yet ready or understand the contact with an HIV person. And, I think it would be a standoffish kind of thing. And, I would rather not deal with that, so I don't go there.

The women who were not currently in a sexual relationship implied that their sexual desires were not great enough to lead them to pursue one. Some reported that they didn't "like sex" or didn't "want to have sex," and others stated they could "take it or leave it" or that it was "not that important" to them. One woman implied that her low level of sexual desire could be attributed to menopause:

I mean, it's not like I crave sex or I want sex. You know, I'm 57, it doesn't even bother me. I could take it or leave it. You know, it don't matter one way or the 
other, it really don't. I guess it's the changes and all that junk, the changes... It don't bother me though.

One woman described some of her conflicting feelings about sex as an older, HIV-infected woman:

I just don't have sex anymore. I just don't want to really. I just don't want to. Because if I have to tell somebody that I have HIV, I would just as soon not have it. It doesn't bother me that much anyway. I am 52 years old and like my momma, she said she didn't want no sex after a certain age. I'll just be like my momma. My sister tells me that too. She is about, what, 56. She is 56 and she says, "Hmm, I don't want my old man." [LAUGHTER.] So, I am getting about that way, after so many years. I just say, “Um, no need." It really doesn't bother me anymore. I still be attracted to men and I still talk to them and flirt with them a little bit, but other than that, that's it. I have men that are friends. But, I haven't told any of them. Well, I did tell one of them, but I haven't seen him in a while, so I am kind of upset with him. [LAUGHTER.] But other than that ... I don't have any men, just some acquaintances and stuff like that.

Conversely, women who were currently in sexual relationships did not report feeling negative or apathetic about sex.

The women were asked about differences between younger and older women with regard to sex. Refraining from risky sex was seen as easier for older women because sex and intimate partnerships were less important for them than they were to younger women:

For older women, um... usually when you get my age, you just want to be somewhere and be quiet anyway. You don't want all of the ... I mean, you want a companion, but it is not as important to you at 50 as it is at 20. You know marriage and that kind of stuff. So, I think that it is harder for younger women.

\section{Spirituality and Church Relationships}

Although the women were not asked specifically about spirituality or religion, all 15 talked during their interviews about their close personal relationship with God, whom they felt supported them in living with HIV. Fourteen participants reported attending church. Many described how they benefited from engaging in social activities, doing church work, and receiving instrumental support, such as when other church members take their garbage out. One woman stated: "The church is you! You know, it's who you be, you know. I just enjoy the people, I enjoy myself. I love myself, so automatically I love other people, you know."

The women described many ways that God helped them. Specifically, the women said that God helped them or gave them strength to sustain healthy behaviors, such as taking medications, abstaining from unprotected sex with an HIV-uninfected partner, discontinuing substance abuse, managing comorbid conditions, and maintaining sobriety. Regarding her sobriety, one woman stated: "[God] took the want, the thirst, and the taste for that drug away." They also said that God intervened in their health directly, by keeping their viral loads low, helping them to find housing and transportation, keeping them from acquiring additional co-morbid conditions, and alleviating emotional distress. One woman 
summarized this by saying, "I feel like I'm fine as long as I have Jesus in my life. I know that he will provide for me what I need and what I need to get by each and every day."

The women referenced God most often during discussions of hardships, such as trauma, substance abuse, and HIV infection. One woman's faith helped her cope with having mistreated her children while using substances.

Sometimes I myself still have problems with it because I think back to things I did to [my children] and ways that I mistreated them and the problems with the life that I was leading. But, I just have to put it under the blood and say that now I belong to Jesus and that Jesus is in my life and I trust in him each and every day and that sort of pushes it off to the side.

Many women said that God helped them cope with their initial HIV diagnosis, especially when they were unable to confide in others. One woman said,

I am not sure that I would have made it through the initial shock and acclimation to it all without my faith. There have been many times when I didn't have anyone to talk to, and I had to talk to God.

Another woman speculated that the reason she was infected with HIV was to bring her closer to God.

In spite of strong relationships with God, many women reported limiting the amount they relied on their church for support. As one woman put it,

My momma taught me a valuable lesson. It was a hard, cold one, but it was a valuable one. My lights, when me and my kids was going through, my lights got cut out and I had been with my momma in church every Sunday by her side. One day I said, "Momma, I'm going to see if the church can help me get my lights back on." "Don't ask the church for no money! You can't go asking for money here!

There ain't nothing down there for you."

Many women described ways in which they cultivated a private relationship with God through activities, such as daily prayer, Bible study, and watching religious television programs. One woman described her practice this way:

Yeah, I read the Bible every day. And I pray every night, every night. That's how... Sometimes if I don't pray then I'll say, “Now, did I say my prayers?" In case I didn't, I say them again to make sure.

Another woman stated:

I talk to the Lord just like I'm talking to you. If there's anything I'm worried about, if I'm worried about my health or anything, I talk to him. And I can feel the spirit changing in a positive aspect. If I don't get a feeling in my spirit that everything is going to be alright, he'll tell me in my spirit a scripture to go ahead and read in my Bible that will help me to understand what I am going through at that time and that helps me also. 
Almost all of the women who attended church reported they chose not to disclose their HIV status to fellow church members or pastors for fear that church members would be afraid of catching HIV from them and would gossip about them. One woman stated:

I made the right decision because a lot of people because they don't know and they're not interested in finding out because of their fear and their ignorance - they just don't want to know. And because of that, they would be fearful being around me and near me.

Another woman described why she wouldn't tell her minister about her HIV status:

... in my generation a lot of the Biblical things they do not condone premarital sex. So, if you are participating in that and you got HIV, you got the virus, then it's sortof, well, "If you had not been sinning then you would not have it." You know that kind of thing. So, would I tell my minister? No. Although I think that he is broadminded. But, not that... Well, I think that he still would be truthful in his doing. He don't condone premarital sex. He's one of those.

Two women chose to disclose their status only to their pastor, "in case I got injured so others wouldn't be exposed to HIV." In contrast to these women's reticence regarding their HIV status, two other church-going women in this sample who had histories of substance abuse reported testifying to their congregations about their struggles with using substances and offering their support to fellow church members with similar problems.

\section{Discussion}

This study is one of the first to qualitatively explore the real life experiences of older women living with HIV in the Southeastern United States. The findings from this study highlight several important themes related to aging with the disease, and specifically how older women experience support from different types of relationships and spiritual sources.

Although the women in this study reported receiving some instrumental and emotional support from a variety of sources, particularly family and friends, many felt socially isolated, lonely, and fearful of repercussions they would suffer should their HIV status became known to others. The women felt that, because they were older, their HIV status would be viewed even more shamefully than it would for younger women living with HIV. Many reported generally limiting their social interactions because they worried that others would become fearful of contracting HIV from them through casual contact. Notably absent from these women's comments about sources of social support was specific mention of their HIV care settings. We report elsewhere that these women reported generally positive relationships with their HIV care providers, but none specifically mentioned receiving support from them (Grodensky, Golin, Jones, Mamo, Abernethy, \& Patterson, unpublished manuscript).

Consistent with another study of older HIV-infected women, few of the women in our study received support and companionship through romantic partnerships (Lovejoy et al., 2008). Most women reported the dissolution of prior romantic relationships after the HIV diagnosis, and most did not pursue new relationships for fear of infecting someone else and 
wanting to avoid having to disclose their serostatus. Many women also reported feeling that having a sexual relationship was not highly important to them, with some specifying that this feeling was related to their age or menopause. It was unclear from our research whether this lack of interest in sexual relationships among menopausal and post-menopausal women was heightened in this sample due to HIV infection; further research is needed to explore the relationships between sexual interest and HIV infection in older women.

Our findings of feelings of isolation in older women with HIV supported other studies. Social support has been shown to help decrease distress and improve mood for older HIVinfected individuals (Schrimshaw \& Siegel, 2003); in contrast, stigma and loneliness have been associated with higher levels of depressive symptoms (Grov et al., 2010; Yi et al., 2006). Older women with HIV experience isolation (Enriquez, Lackey, \& Witt, 2008) and are less likely to disclose than their younger counterparts (Emlet, 2006a). Older minorities, especially, have smaller social networks and are at greater risk for isolation than older Whites or younger adults (Emlet, 2006b). The social stigmas, whether real or perceived, that older women infected with HIV experience impede disclosure, emotional health, and adherence to HIV treatment (Black \& Miles, 2002; Foster, 2009). Our study contributes to the body of knowledge about these issues by elucidating the specific linkages that exist between HIV-related stigma, disclosure, and social support for older women in several different types of relationships, even with their most intimate family and friends.

Spirituality also emerged as a highly salient theme, and seemed to function as a lens through which the women viewed their lives. The women reported that God helped them cope with disease, refrain from substance abuse, and engage in healthy behaviors. This theme may be particularly prominent in our sample, which was mostly African American, as spirituality has been found to be a stronger source of illness-related coping among African Americans than among Caucasians (Cotton et al., 2006; Harvey \& Silverman, 2007).

It has been well documented that spirituality and prayer can be powerful coping mechanisms for patients living with chronic illnesses (Johnson, Elbert-Avila, \& Tulsky, 2005; Koenig, Larson, \& Larson, 2001). This benefit has also been demonstrated for those living with HIV (Vance, McGuinness, Musgrove, Orel, \& Fazeli, 2011). Spiritual peace has even been found to moderate the effects of HIV stigma on depression (Chaudoir et al., 2012). However, religion can also be a source of stress and low self-esteem for those who feel condemnation from the church due to their actions or sexual orientation (Nicholson, 2009). The women in this study reported feeling real and anticipated HIV stigma from their church communities, limiting disclosure and participation at church and depriving them of an important source of social support. Studies have found that HIV stigma present in African American churches may explain HIV-infected African American women's preference for engaging in private spiritual practice (Cotton et al., 2006; Foster, 2009; Peterson, 2009; Vance, Brennan, Enah, Smith, \& Kaur, 2011). The women's perspectives in our study drew particular attention to the conflict that can exist between the tremendous potential benefit from a church community and spiritual life and the limitations they encountered in fully engaging due to the issues of HIV-related stigma and disclosure, a conflict that may be particularly strong among older women in the South. 
The women in our study described detrimental effects of decreased social support and HIVrelated stigma in their lives as well as benefits of their spiritual strength, factors that have been explored in prior research (Vance, Brennan, Enah, Smith, \& Kaur, 2011). Building on work from the field of gerontology (Kirk \& Goetz, 2009), Vance, Brennan et al. 2011) postulated that for HIV-infected older adults, the stressors of decreased social support and HIV-related stigma act as barriers to successful aging, particularly to active engagement in life and spirituality within a developmental context. Spirituality and religion, on the other hand, could serve as buffers to these stressors by allowing individuals to interpret their life experiences in the context of their beliefs, which provide purpose and meaning in life, as well as promoting transcendence over circumstances. (Fuchs, Czeh, Kole, Michaelis, \& Lucassen, 2004; Parker et al., 2002; Vance, 2004; Vance, Ross, Moneyham, Farr, \& Fordham, 2010). The women in our study reported that stigma both inhibited their disclosure and decreased their social support, suggesting that decreased social support may mediate the effect of stigma on successful aging. Furthermore, older women's abilities to engage in religious and spiritual communities may in itself be inhibited by stigma and decreased social support, implying that in order for religion and spirituality to buffer life's stressors, the specific barrier of stigma may need to be addressed.

\section{Limitations}

The 15 women who participated in our study were recruited from a single HIV clinic in the Southeastern United States and were predominantly African American; therefore, these results cannot be widely generalized to other settings or populations. All of the women in our study were currently receiving HIV care, and their experiences may have been different from older HIV-infected women who were not receiving care. We employed qualitative research methods, which allowed in-depth exploration of these phenomena, but we were not able to test for statistically significant relationships or to make comparisons between the factors of interest.

\section{Research and Clinical Implications}

The findings from this study suggest several implications for intervention research and clinical practice with older women living with HIV. A lack of HIV knowledge and high levels of HIV stigma in communities may be amenable to community-level interventions. Targeting HIV-directed interventions through spiritual communities may confer additional benefits of increased spiritual support and religious engagement for older women living with HIV, for whom spirituality and church participation may be beneficial. Additionally, incorporating spirituality into counseling for older women living with HIV may enhance engagement with and benefit from mental health, substance abuse, and health education programs (Vance, Brennan, Enah, Smith, \& Kaur, 2011). Programs that link HIV-infected women together may increase their sources of emotional support and ability to employ positive coping (Enriquez et al., 2008). In clinical settings, health care providers should be aware that older women living with HIV may lack social support for coping with and managing HIV infection, and that disclosure may be a key barrier to accessing this support. Nurses and other clinical staff can provide support to older women by helping them make decisions about disclosure and to disclose to individuals who may be able to provide support. 


\section{Conclusions}

The findings of our research elucidated critical issues impacting the ability of older HIVinfected women in the South to receive needed social and spiritual support. This increased understanding about the interplay of HIV-related stigma, disclosure, and spirituality is important to consider when developing future directions for HIV care and research with older women living with HIV, a group that will continue to increase as people live longer with HIV. Focusing attention on the needs of this group will help to ensure that older women are able to age successfully with HIV.

\section{Acknowledgments}

This research was supported by NIH grant K23 AI077355 (KBP), and the University of North Carolina at Chapel Hill Center for AIDS Research (CFAR), an NIH-funded program P30 AI50410. We are grateful to all study participants, and to Randall Teal of the UNC Communication for Health Applications and Interventions Core (supported by NIH programs P30 DK56350 and P30 CA16086) for assistance with manuscript review.

\section{References}

Barclay TR, Hinkin CH, Castellon SA, Mason KI, Reinhard MJ, Marion SD, Durvasula RS. Ageassociated predictors of medication adherence in HIV-positive adults: Health beliefs, self-efficacy, and neurocognitive status. Health Psychology. 2007; 26(1):40-49.10.1037/0278-6133.26.1.40 [PubMed: 17209696]

Black BP, Miles MS. Calculating the risks and benefits of disclosure in African American women who have HIV. Journal of Obstetric, Gynecologic, and Neonatal Nursing. 2002; 31(6):688697.10.1177/0884217502239211

Byers AL, Yaffe K, Covinsky KE, Friedman MB, Bruce ML. High occurrence of mood and anxiety disorders among older adults: The national comorbidity survey replication. Archives of General Psychiatry. 2010; 67(5):489-496.10.1001/archgenpsychiatry.2010.35 [PubMed: 20439830]

Centers for Disease Control and Prevention. HIV/AIDS among persons aged 50 and older. 2008. Retrieved from http://www.cdc.gov/hiv/pdf/ library_factsheet_HIV_among_PersonsAged50andOlder.pdf

Centers for Disease Control and Prevention. HIV in the United States: At a glance. 2012. Retrieved from http://www.cdc.gov/hiv/resources/factsheets/us.htm

Chaudoir SR, Norton WE, Earnshaw VA, Moneyham L, Mugavero MJ, Hiers KM. Coping with HIV stigma: Do proactive coping and spiritual peace buffer the effect of stigma on depression? AIDS and Behavior. 2012; 16(8):2382-2391.10.1007/s10461-011-0039-3 [PubMed: 21956644]

Cotton S, Tsevat J, Szaflarski M, Kudel I, Sherman SN, Feinberg J, Holmes WC. Changes in religiousness and spirituality attributed to HIV/AIDS: Are there sex and race differences? Journal of General Internal Medicine. 2006; 21(Suppl. 5):S14-S20.10.1111/j.1525-1497.2006.00641.x [PubMed: 17083495]

Effros RB, Fletcher CV, Gebo K, Halter JB, Hazzard WR, Horne FM, High KP. Aging and infectious diseases: Workshop on HIV infection and aging: What is known and future research directions. Clinical Infectious Diseases. 2008; 47(4):542-553.10.1086/590150 [PubMed: 18627268]

Emlet CA. A comparison of HIV stigma and disclosure patterns between older and younger adults living with HIV/AIDS. AIDS Patient Care and STDs. 2006a; 20(5):350-358.10.1089/apc. 2006.20.350 [PubMed: 16706709]

Emlet CA. "You're awfully old to have this disease": Experiences of stigma and ageism in adults 50 years and older living with HIV/AIDS. The Gerontologist. 2006b; 46(6):781-790.10.1093/geront/ 46.6.781 [PubMed: 17169933]

Enriquez M, Lackey N, Witt J. Health concerns of mature women living with HIV in the Midwestern United States. Journal of the Association of Nurses in AIDS Care. 2008; 19(1):37-46.10.1016/ j.jana.2007.09.004 [PubMed: 18191767] 
Ettenhofer ML, Hinkin CH, Castellon SA, Durvasula R, Ullman J, Lam M, Foley J. Aging, neurocognition, and medication adherence in HIV infection. American Journal of Geriatric Psychiatry. 2009; 17(4):281-290.10.1097/JGP.0b013e31819431bd [PubMed: 19307857]

Foster PP. Older African Americans' management of HIV/AIDS stigma. AIDS Care. 2009; 21(10): 1306-1312.10.1080/09540120902803141 [PubMed: 20024707]

Fuchs E, Czeh B, Kole MH, Michaelis T, Lucassen PJ. Alterations of neuroplasticity in depression: The hippocampus and beyond. European Neuropsychopharmacology. 2004; 14(Suppl. 5):S481S490.10.1016/j.euroneuro.2004.09.002 [PubMed: 15550346]

Grodensky, CA.; Golin, CE.; Jones, C.; Mamo, M.; Abernethy, MG.; Patterson, KB. Older women living with HIV in the South: Perspectives on HIV care and antiretroviral adherence. 2014. Unpublished manuscript

Grov C, Golub SA, Parsons JT, Brennan M, Karpiak SE. Loneliness and HIV-related stigma explain depression among older HIV-positive adults. AIDS Care. 2010; 22(5):630639.10.1080/09540120903280901 [PubMed: 20401765]

Gum AM, King-Kallimanis B, Kohn R. Prevalence of mood, anxiety, and substance-abuse disorders for older Americans in the national comorbidity survey-replication. The American Journal of Geriatric Psychiatry. 2009; 17(9):769-781.10.1097/JGP.0b013e3181ad4f5a [PubMed: 19700949]

Harvey IS, Silverman M. The role of spirituality in the self-management of chronic illness among older African and Whites. Journal of Cross-Cultural Gerontology. 2007; 22(2):205-220.10.1007/ s10823-007-9038-2 [PubMed: 17370121]

Hinkin CH, Hardy DJ, Mason KI, Castellon SA, Durvasula RS, Lam MN, Stefaniak M. Medication adherence in HIV-infected adults: Effect of patient age, cognitive status, and substance abuse. AIDS. 2004; 18(Suppl. 1):S19-S25. [PubMed: 15075494]

Johnson KS, Elbert-Avila KI, Tulsky JA. The influence of spiritual beliefs and practices on the treatment preferences of African Americans: A review of the literature. Journal of the American Geriatrics Society. 2005; 53(4):711-719.10.1111/j.1532-5415.2005.53224.x [PubMed: 15817022]

Kirk JB, Goetz MB. Human immunodeficiency virus in an aging population, a complication of success. Journal of the American Geriatrics Society. 2009; 57(11):2129-2138.10.1111/j. 1532-5415.2009.02494.x [PubMed: 19793157]

Koenig HG, Larson DB, Larson SS. Religion and coping with serious medical illness. The Annals of Pharmacotherapy. 2001; 35(3):352-359. [PubMed: 11261534]

Lincoln KD, Taylor RJ, Chae DH, Chatters LM. Demographic correlates of psychological well-being and distress among older African Americans and Caribbean Black adults. Best Practices in Mental Health. 2010; 6(1):103-126. [PubMed: 21765812]

Lovejoy TI, Heckman TG, Sikkema KJ, Hansen NB, Kochman A, Suhr JA, Johnson CJ. Patterns and correlates of sexual activity and condom use behavior in persons 50-plus years of age living with HIV/AIDS. AIDS and Behavior. 2008; 12(6):943-956.10.1007/s10461-008-9384-2 [PubMed: 18389361]

Nguyen N, Holodniy M. HIV infection in the elderly. Clinical Interventions in Aging. 2008; 3(3):453472. [PubMed: 18982916]

Nicholson NR Jr. Social isolation in older adults: An evolutionary concept analysis. Journal of Advanced Nursing. 2009; 65(6):1342-1352.10.1111/j.1365-2648.2008.04959.x [PubMed: 19291185]

Parker MW, Bellis JM, Bishop P, Harper M, Allman RM, Moore C, Thompson P. A multidisciplinary model of health promotion incorporating spirituality into a successful aging intervention with African American and White elderly groups. The Gerontologist. 2002; 42(3):406-415.10.1093/ geront/42.3.406 [PubMed: 12040144]

Peterson, JL. Spirituality provides meaning and social support for women living with HIV. In: Brashers, DE.; Goldsmith, DJ., editors. Communicating to manage health and illness. 1. New York, NY: Routledge; 2009. p. 301-321.

Rabkin JG, McElhiney MC, Ferrando SJ. Mood and substance use disorders in older adults with HIV/ AIDS: Methodological issues and preliminary evidence. AIDS. 2004; 18(Suppl. 1):S43-S48. [PubMed: 15075497] 
Ryan GW, Bernard HR. Techniques to identify themes. Field Methods. 2003; 15(1):85109.10.1177/1525822X02239569

Sandelowski M, Barroso J. Classifying the findings in qualitative studies. Qualitative Health Research. 2003; 13(7):905-923.10.1177/1049732303253488 [PubMed: 14502957]

Sankar A, Nevedal A, Neufeld S, Berry R, Luborsky M. What do we know about older adults and HIV? A review of social and behavioral literature. AIDS Care. 2011; 23(10):1187-1207. doi: 0.1080/09540121.2011.564115. [PubMed: 21939401]

Schrimshaw EW, Siegel K. Perceived barriers to social support from family and friends among older adults with HIV/AIDS. Journal of Health Psychology. 2003; 8(6):738752.10.1177/13591053030086007 [PubMed: 14670207]

Stark SW. The aging face of HIV/AIDS. American Nurse Today. 2007; 2(6):30-32.

Vance DE. Cortical and subcortical dynamics of aging with HIV infection. Perceptual and Motor Skills. 2004; 98(2):647-655.10.2466/pms.98.2.647-655 [PubMed: 15141931]

Vance DE, Brennan M, Enah C, Smith GL, Kaur J. Religion, spirituality, and older adults with HIV: Critical personal and social resources for an aging epidemic. Clinical Interventions in Aging. 2011; 6:101-109.10.2147/CIA.S16349 [PubMed: 21753865]

Vance DE, McGuinness T, Musgrove K, Orel NA, Fazeli PL. Successful aging and the epidemiology of HIV. Clinical Interventions in Aging. 2011; 6:181-192.10.2147/CIA.S14726 [PubMed: 21822373]

Vance DE, Ross JA, Moneyham L, Farr KF, Fordham P. A model of cognitive decline and suicidal ideation in adults aging with HIV. The Journal of Neuroscience Nursing. 2010; 42(3):150 156.10.1097/JNN.0b013e3181d4a35a [PubMed: 20550075]

Yi MS, Mrus JM, Wade TJ, Ho ML, Hornung RW, Cotton S, Tsevat J. Religion, spirituality, and depressive symptoms in patients with HIV/AIDS. Journal of General Internal Medicine. 2006; 21(Suppl. 5):S21-S27.10.1111/j.1525-1497.2006.00643.x [PubMed: 17083496] 


\section{Key Considerations}

- Health care personnel should inquire about the source of social support for HIVinfected older women. While many older women have supportive family members, others have not disclosed to family members and therefore cannot request assistance in HIV-related health care.

- Health care providers should strive to understand each woman's intentions and desires for support in the event she is unable to communicate these herself. Additionally, women may require guidance and support to request external support needed to maintain maximum health and health care.

- Nurses can be strong advocates in helping HIV-infected older women disclose their HIV status to a trustworthy source. Knowing to whom HIV-infected women have disclosed can facilitate communication between care providers and patients.

- Nurses can provide validity to knowledge or help to change false pretenses related to transmission.

- Most importantly, nurses are often the face of the HIV clinic. Knowing that nurses can be trusted, are their advocates, are nonjudgmental, and see "beyond the HIV," will encourage women to remain in care and adhere to their ARVs. Over time, this trusting relationship will allow HIV-infected older women to recognize that HIV does not define who they are, helping these wise women educate others in their communities. 
Table 1

Demographic Data for HIV-Infected Older Women $(n=15)$

\begin{tabular}{|l|c|}
\hline Variable & $\boldsymbol{n}(\%)$ \\
\hline Ethnicity & $13(87)$ \\
African American & $2(13)$ \\
Caucasian & $57(50-79)$ \\
\hline Age, mean years (range) & \\
\hline Marital status & $2(13)$ \\
Married & $9(60)$ \\
Divorced & $4(27)$ \\
Widowed & $15(100)$ \\
\hline Mode of HIV acquisition & \\
Heterosexual intercourse & $9(60)$ \\
\hline Substance use & $6(40)$ \\
History of drug/alcohol abuse & $2(13)$ \\
• Current use of crack or cocaine & $4(27)$ \\
\hline C Current use of intravenous drugs
\end{tabular}

* Two participants (13\%) were missing data on current and past substance use. 